\title{
Human Centred University Commercialisation
}

\author{
Tom McEwan \\ Centre for Interaction Design, \\ Edinburgh Napier University \\ Edinburgh EH10 5DT, UK \\ +441314552793 \\ t.mcewan@napier.ac.uk
}

\begin{abstract}
Universities in the UK need to develop commercial revenue streams to fill funding gaps, and also, to help justify continued public funding, to stimulate innovation and enhance the economy. Information technology (IT) is the source or catalyst for much innovation, historically this been based on much university input. Human-centred design (HCD) approaches, based on research from Human-Computer Interaction and related fields have been shown to be more effective than technically-driven approaches to achieve sustainable innovation based on IT.

However commercialisation requires IT academics to acquire new expertise in business innovation and while sources of this are undoubtedly market- and customer-focused, they tend not be human-centred. At the same time, individual academics may simply not engage with efforts to stimulate commercialisation as they see many personal risks they often feel unable to manage. If commercialisation is to take place, these human factors also need to be addressed.

This paper reflects on successful experiences of applying HCD over ten years of collaboration with industry and considers how to extend these approaches into commercialisation (where, in many ways, universities will now compete with industry). Unexpectedly, a need emerges to clarify the definitions of terms such as innovation and research and development (R\&D), in order to meet the varied expectations and requirements of policy makers, public funders and potential investors. Based on engagement over two years with around forty academics on a range of commercialisation ideas, a PACT analysis [1] illustrates the human factors involved in university commercialisation. Further studies are proposed.
\end{abstract}

\section{Categories and Subject Descriptors}

K.6.1 Project and People Management, H.1.2 User/Machine Systems

\section{General Terms}

Human Factors

\section{Keywords}

HCD, Commercialisation, Innovation, PACT Analysis

\section{INTRODUCTION}

Despite steady improvements in their international reputation for research and teaching, UK Universities face a growing

(c) The Author 2009.

Published by the British Computer Society funding gap. "Third stream funding", to promote commercial and knowledge transfer (or knowledge exchange) activities, is intended to fill this growing gap, but this remains small (around $2.5 \%$ of total UK university funding). Of course, such activity is intended to become self-funding, and ultimately create revenue streams to universities, based on licensing of intellectual property (IP) or sale of equity in spin-out companies (though, throughout the world, successful universities rarely derive more than $3 \%$ of their total income from commercialisation). However there are no guarantees of success, indeed a very high probability of failure is accepted as the norm. Even muchvaunted successes can have a short shelf-life, and collapse after a few good years. Human factors issues can be seen in the numerous failures, for example:

- The "brilliant academic" who leave the university and achieves success with ground-breaking technology, but who has neither the skills (nor the training) to run a business of more than fifty people, nor the time to research the next generation breakthrough that sustains the business five years later. The company then disintegrates.

- The part-time chief technology officer whose teaching and research commitments prevent them from being immediately available to motivate and manage the technical team. Key team members leave due to overwork and lack of structured career progression.

- The recent $\mathrm{PhD}$ who launches themselves wholeheartedly into the business that is built on their ideas, only to find themselves edged out of the board and then the company, as repeated rounds of funding dilute their equity stake, and each new investor makes incremental changes to the directors and the management structure.

- The research that produces high volumes of well-regarded literature, but when eventually brought to market, after considerable investment, the resulting products do not suit the needs of customers, sales are poor and the investors lose everything.

In each case, considering the human needs of both the creator and the end-user of technology, as well as the more traditional business objectives such as "identify the market", "provide return on investment" and "attract investor confidence", ensures that innovation becomes sustainable. This paper considers what is needed for a human-centred approach to university commercialisation, and contains reflection on around two years capacity-building in this area. The paper starts with a brief discussion of the different approaches to innovation and commercialisation that are available, particularly with reference to technology-based innovation. The next section reflects on a much longer period of trying to apply HCD in a related activity - collaboration with companies via mechanisms such as knowledge transfer partnerships (KTPs) [2], and from this identifies some strategies that might help ensure that HCD approaches survive in the commercialisation processes

Based on reflection of an engagement with a community of around forty academics with an interest in commercialisation, a 
PACT analysis [1] exemplifies the issues and future work, to develop and validate personas and scenarios, is proposed.

\section{DIFFERENT WAYS TO BUILD VALUE}

Commercialisation and innovation are intended create value, based upon sustainable flows of resource. The classic approach is drawn from US-based technology universities such as MIT and Stanford (eg [3]). These were extremely successful in the 1990s (eg 3Com), unsuccessful in the dotcom era and now don't seem to chime, at least within Europe, with the rise of human-centred approaches. The approach taken is capitalistic in its narrowest sense - by obtaining a large amount of capital and burning through it rapidly, momentum can be built - to be early to market, capture global market share and charge the highest viable price. The rewards then return to those who provide the capital, with whatever is left for those who provide ideas. This is considered fair as, in most cases, the business fails, investors lose all their investment. The occasional success pays for the many failures.

The drivers for university commercialisation are complex. They are rooted in government desires for global competitiveness and the need to foster innovation to sustain and then increase the nation's gross domestic product (GDP). Senior politicians in the UK, such as Prime Minister Gordon Brown and the Trade Secretary Lord Mandelson, have repeatedly stated (in early 2009) the need for university-driven innovation to lead the UK out of the current recession. Since the policy decisions by the eEnvoy in 1999, the UK government has had a commitment to ISO 13407 [4] and using human-centred design (HCD) approaches in public sector IT. It is reasonable to expect that public-funded IT innovation by UK universities will be based on HCD - and there are numerous case studies globally (such as [31]) showing the financial benefits of using HCD.

The trends away from manufacturing to service sector, and now to "knowledge jobs" (whether in manufacturing or service sectors), increasingly demands the participation of universities in the economy both to equip graduates to cope with new forms of employment, and to define new knowledge-based businesses. This has resulted in a global trend to mass higher education, Despite press coverage to the contrary, UK citizens have been loath to participate, with small increases in participation in some parts of the country and decreases in others, all far short of the government's commitment to achieve $50 \%$ participation (which is still relatively low in global terms). As a result the UK has fallen to $35^{\text {th }}$ out of 40 sampled countries for $\mathrm{HE}$ participation despite being $9^{\text {th }}$ out of 40 for total spending on HE [5]. Additionally, university participation in the UK has a pronounced class divide [5]. All of this establishes a tension between citizen and society.

Thus universities need to be seen to contribute to the wider economy through application of research, if they are to help justify their current levels of state subsidy against the populist arguments such as - "why should the children of plumbers subsidise the children of lawyers?" This issue - of the value of universities to the economy was at the heart of the UK Lambert Review [6].

\subsection{Lambert Review}

This report identifies both a need for industry to exploit university research in order to maintain the UK's economic position, yet also a lack of demand in industry for academic input. It also identifies divergent trend in state funding of research in the UK and the US. In the 1990s each invested broadly comparable shares of GDP, but by 2003 the share in the UK was one third less than their US counterparts [6 - section 6.45]. Lambert commends Chesbrough's notion that Open
Innovation can compensate for the steady global reduction in basic research carried out in industry, but tends to conflate innovation with research \& development (R\&D) and many would now argue that the two are not necessarily the same. Open Innovation itself does not appear to be intended to provide universities with a revenue stream - quite the opposite appears to be the assumption of [7], who considers any formal protection of IP by universities to slow down innovation, and characterises universities as doing basic research which is not immediately commercially exploitable. There assertions now seem over-simplistic, and in particular in reference to both applied research and the social science nature of HCD.

It is beyond the scope of this paper to fully analyse Open Innovation but, on first sight, this approach seems intended to serve the interests of large organizations who wish to access the $99 \%$ of relevant expertise that resides outside their organization. The corollary is that the external providers of said expertise have to be sophisticated and robust in claiming their fair share of added value. Yet Lambert, like Fabrizio [7], rejects the US approach of universities owning all IP in joint public-private funded research (s 4.28-29). In any case formal IP protection, such as patenting, is contentious enough in hardware and software development, and harder still to apportion in collaborations that deliver the benefits of, say, enhanced design and service definition through HCD. Benefits to industry of working with a university are summarised by Lambert as being "more likely to have increased their market share, improved the quality of their goods and services and lowered their costs" (s. 2.38). Lambert observes that British managers lack scientific training (s. 2.22), that fewer than $20 \%$ of businesses engage with universities (s. 2.23) and that there is a fundamental lack of desire in business to work with universities (s. 2.60). This will be familiar to those who try to bridge industry and academia media coverage (such as popular TV shows You're Fired and Dragon's Den), portrays successful UK entrepreneurs in the UK wearing their lack of university qualifications with pride.

Lambert does present some case studies of British universities collaborating successfully with industry to innovate. Yet none of the examples could be said to be HCD - the closest is an example where university input benefitted "aesthetics, functionality and ease of manufacturer" (s. 2.51). But ultimately Lambert seems confused and confusing as to why and how universities collaborate with industry: the low level of US patents in UK universities is claimed to be evidence of a lack of world class innovation (s. 4.6); that Germany has more patents but fewer citations than the UK, per head of capita, is presented as evidence that Germany is better at bringing university ideas to market (s. 6.43); the report's unqualified acceptance of Open Innovation requires more analysis. Nevertheless this report has been influential in policy and in funding to support innovation.

There is clearly a political, social and economic rationale for university commercialisation and it attracts a comparable range of support measures, each addressing aspects of those agendas. It also takes place in a context (entrepreneurialism and the marketplace) where opportunism and exploitation are generally seen as virtues, and many demand-side participants (ie investors) are highly motivated by money and power rather than any other type of reward. While this is not absent on the supplyside, (ie universities, their staff and students), there is generally a more liberal-minded consensus, and as both [6] and [7] point out, desired reward for academics is as much in esteem and in a sense of accomplishment, as financial. The clash of these two cultures is not as overt or as frequent as one might suspect, but remains dormant beneath the surface, is not hard to awake, and, in our experience, even small perturbations can rapidly swamp a fragile idea that might lead to innovation. 


\subsection{Accessing Entrepreneurial Expertise}

An industry exists to service would-be UK university entrepreneurs. Indeed there is possibly more entrepreneurialism in the advice than the results. This pattern is reminiscent of the multimedia industry in the early 1990s. Then the companies (eg Adobe, Macromedia) making the development tools achieved far more success than the companies that bought these tools. Caution is advisable when faced by the hype of those who promise success. For university commercialisation, there exists an array of consultants offering expensive advice, motivational and business training courses, business plan preparers, feisty chief executive officers for hire (at $£ 100 \mathrm{k}$ salaries) to add reality to academics' other-worldliness, public sector departments offering training, advice and grants. Ultimately this industry focuses on individual professors, lecturers, research associates and fellows who already have ambitions within their discipline, career and family life. Our observations are that, at best, this industry supports academics to shift, or at least suppress or disguise, their aspirations and at worst can force them down paths contradictory to their values and does not even deliver commercial success.

\subsection{Differentiating $R \& D$ \& Innovation}

All of this takes place within a context in which governments seek to foster innovation and wealth creation, within which R\&D currently has a contested significance: "Supply-side indicators such as expenditures on research and development (...) fail to capture the true innovative activity in sectors such as financial services, retail, consultancy and the public sector" [8]. For many, R\&D is seen as a driver of innovation [9] and wealth creation, yet others find no causality or limited correlation. These nuances are often not reflected in the regulations for funding instruments. Similarly the value of human-centred approaches in the innovation cycle is not always recognised. From the Madison Avenue approaches of fifty years ago to the persuasion marketing of today, it's not hard to find examples that confirm the suspicion that the predominant game is to persuade people who can't afford it - to "buy things they don't need" [10].

As the HCI community dives ever deeper into affect, emotion, pleasure, user experience and hedonics, are we on the side of the hawks or the angels? A more positive, though to some idealistic, perspective was heard in Kees Dorst's keynote at HCI2004 (summarised in [11]) which identified how the designer can and should achieve the shift from company-led innovation to user-led innovation. Dorst suggests that more effective innovation results when the designer engages with a community to research their needs and develops prototypes and then products that meet these needs. Only then is the manufacturer approached. This is in contrast to the traditional route of manufacturer carrying out market research to see what would sell then commissioning the lab to design and develop the product, then strongly marketing the resulting innovation.

The OECD has been reviewing [12] the role of innovation, $\mathrm{R} \& \mathrm{D}$ and economic development. It is pointed out that investment in $\mathrm{R} \& \mathrm{D}$ does not necessarily correlate with innovation nor with economic development, and that there are trends depending on the maturity and size of the economy. An example discussed at a recent seminar was a local chef who was known for their innovation, and who spent a large part of the year travelling to other countries to explore and experiment with other cuisines in their original context. From an HCD perspective this seems a commendable approach, but in terms of gathering statistics for $R \& D$, it appears that the research investment made by this chef would be excluded, categorised as marketing or market research expenditure. It's clear that a similar constraint may apply to many HCD activities within $\mathrm{R} \& \mathrm{D}$ - the time spent studying users might be ignored by those collating $R \& D$ evidence, no matter how much this contributed to both innovation and enhancing GDP.

A typical HCD approach to innovation is [13] - where the user experience (UEX) team gained equivalent influence to the teams that defined scope/specifications and carried out quality assurance, respectively. This then ensured that user experience issues were addressed more at the scoping stage than at the post-implementation stage. However it seems doubtful that such UEX scoping efforts would be classed as R\&D - this then becomes significant if funding resulting from Lambert's recommendations is restricted to activities categorized as R\&D. This paper also cites the iPod as a counterexample to Drucker's insistence that the software industry is not innovative. As will be described in the following section, portable music players were in the marketplace well before the iPod and it's arguable that this was not a technical innovation, but one of styling and an effective business model - again, both areas would not be classed as R\&D.

OECD manuals [14] [15] contain the definitive methods used to measure R\&D. Searching the former 254 page document for terms such as "user(s)" produces only mention of users of R\&D data itself. The overall view of product development here is a waterfall methodology with brief mentions of prototyping and trials. But there is no indication of participative and iterative approaches and no reference to, for example, ISO 13407 [4]. Marketing, Design and Requirements, and related activities, are specifically singled out as "non- $R \& D$ forms of innovation" eg the Oslo Manual lists the following as non-R\&D forms of innovation: "acquisition of disembodied technology and knowhow, (...) industrial design (...) and marketing for new or improved products".

Yet there are other areas where the HCD agenda is included. OECD's basic definition of R\&D does leave the door open to include investigations into users' needs and context, though the emphasis is clearly on generic rather than specific: "Research and experimental development $(R \& D)$ comprise creative work undertaken on a systematic basis in order to increase the stock of knowledge, including knowledge of man, culture and society, and the use of this stock of knowledge to devise new applications."

But even when design is acknowledged as $R \& D$ it may be difficult for the statistic gatherers to recognise it in participatory design, ethnographic studies, stakeholder interviews etc if they follow this guidance (bold highlights have been added):

"The vast bulk of design work in an industrial area is geared towards production processes and as such is not classified as $\boldsymbol{R} \& \boldsymbol{D}$. There are, however, some elements of design work which should be considered as $R \& D$. These include plans and drawings aimed at defining procedures, technical specifications and operational features necessary to the conception, development and manufacturing of new products and processes." (page 44, item 124). Broad and narrow interpretations of "new" would lead to different results. Certainly incremental improvements after evaluation to a product would seem to be excluded. Again, would the iPod development be classed as R\&D under this definition?

The cumulative effect of these statements appears to marginalise Action Research, reflective practice, and HCD practices in general. The definition (pages 46-48) seems to exclude the four key areas identified by [16] as the basis of ISO 9241-210 (the ongoing updating of ISO 13407):

1. Understand and specify the context of use (including users, tasks, environments); 
2. Specify the user requirements in sufficient detail to drive the design;

3. Produce design solutions which meet these requirements;

4. Conduct user-centred evaluations of these design solutions and modify the design taking account of the results.

Elsewhere in [14] and [15], there are statements that in particular exclude social science methods (and ISO13407 approaches) from R\&D: "projects of a routine nature, in which social scientists bring established methodologies, principles and models of the social sciences to bear on a particular problem, cannot be classified as research." The manuals do, however, succumb to the 1990s sentiments about the "internet changes everything!" It seems inconsistent to state that R\&D includes:

" $R \& D$ related to electronic banking and insurance, Internetrelated services and e-commerce applications." and

" $R \& D$ related to new or significantly improved financial services (new concepts for accounts, loans, insurance and saving instruments)."

A more detailed analysis is needed of both the Frascati and Oslo manuals and the funding instruments that rely on them. Work is needed to analyse the methodologies used to record innovation and R\&D, and the capacity to recognise HCD activities and contributions within these methodologies. For the time being, it must be accepted that HCD practices lie mainly outside the scope of R\&D, though they are accepted as part and parcel of innovation. This is not pedantry: when policy makers decide that they need to support R\&D (as opposed to innovation) in order to "get the economy moving", it is possible, even probable, that the funding and resulting initiatives will deny funding to HCD approaches, with the result that far from fostering economic growth, technological white elephants will be built that are neither useful nor used. In our experience, while some of Scottish Enterprise's funding packages permit activities such as market research, user manuals and field tests, others, for example, would exclude stakeholder interviews and selling of prototype products.

At the very least if we want to tap into funds to foster economic growth by encouraging innovation, HCD proponents need to be prepared to explain to the funders the value of aspects of the innovation process that others consider non-R\&D.

\subsection{Entrepreneurial Models}

What does human-centred innovation and commercialisation, from within a university research centre, look like? From our experience there are three main human challenges:

- Gaining innovators' mindshare - being consistent with the aspirations of the individual academics who have many competing bids for their attention, ambition and time.

- $\quad$ Reaching the end-user - arranging an engagement with users and potential customers - which is harder than might be anticipated - student focus groups do not represent the whole market!

- $\quad$ Being understood by other stakeholders - translating propositions from academic into commercial language in order to leverage the required funds from public and private sources.

The Stanford/MIT model appears to be dominant model in the "start-up industry". In this model, academic researchers seek out hardnosed commercially experienced Chief Executive Officers (CEOs) and marketing managers, along with the venture (or more accurately "angel") capital needed to pay their salaries, burn cash until the business turns the corner and then hits solid growth. The more cash burnt, the bigger the potential growth (if successful!). Sometimes known as the hockey-stick curve, or the contrast between A-curve and the B-curve [3], the emphasis here is on large capital investment (in both tools and premises), speed to market, momentum, aggression and the kind of swagger that was prevalent in the dotcom era 1999-2000. There's no denying that this has proved extraordinarily successful in some cases, but there are two challenges. Firstly the inbuilt attrition rate (typically only one in ten achieve success) means that there is much wasted activity (and possibly more nuanced HCD loses out to brash opportunist fashions) and secondly that the cost of the capital required to bring in these management teams, and the rate of return on investment (ROI) expected of the success, means that benefits in the occasional success largely accrue to the investors rather than the innovators, if the latter wishes to stay with the company as it grows. It's not unusual at each funding stage for investors to seek an exit within 4-5 years and ten-fold return on investment, in return for, say, $40 \%$ of the equity, thus diluting the innovator's share further each time.

An alternative model is the organic, self-sacrificial growth process, which the author experienced as technical director of an unfunded start-up that grew over 4 years from 2 people to 60 , and a turnover of $£ 2 \mathrm{~m}$ from a standing start. In the early months no-one drew a salary and instead funded themselves from other sources, then as the business grew, so did salaries and head-count. Those who made the early sacrifices became the senior members of staff. This requires tight cash control, high levels of personal commitment and a very favourable climate for the business products. It also depends on fairness in the apportionment of the equity or else key members of staff leave and precipitate the end of the business just at the point when it might have made a breakthrough.

Other models include co-operatives and social enterprises. The latter have come to the fore during the period that the Labour Party has been in power in the UK, and have spawned a variety of terms [17] to describe alternative measures of success. Many of these success definitions are more in keeping with the values of many in the HCI community.

Having observed a number of seminars by leading entrepreneurs recently, as well as the aforementioned TV shows, it appears that the successful entrepreneur is intuitively a rule-breaker who tends to follow their nose to get to what seems like important. When these individuals train would-be entrepreneurs, their pedagogical approach is rooted in their own experience, which makes for an entertaining and relevant sounding session, but runs the risk that the lesson is simply to be and do more like them. This orthodoxy reflects a particular entrepreneurial culture which may put off potentially viable entrepreneurs, while encouraging blusterers, with sentiments like:

- $\quad$ starting a business means you will work $24 \times 7 \times 365$

- you need lots of capital and you burn through it to create a much bigger business

- most businesses will fail but you gotta try

All of this reflects a somewhat macho view of start-up as needing a sort of wild-west pioneering hero, and seems increasingly outdated. The reality is there are many tiny businesses that are perfectly viable with only a few hours work each week, that businesses can and do (and ought to in the current climate) grow organically through sales rather than burning through investment and loans, and that attention to detail and careful planning can ensure that marginal businesses can steadily build success. 


\section{HCD \& KNOWLEDGE TRANSFER}

For ten years our Centre for Interaction Design has attempted to follow an HCD approach to knowledge transfer [18]. This has been in keeping with philosophies from ISO 13407 [4], the reflective practitioner [19], expertise sharing [20] rather than technology transfer, and informed by models of technology diffusion [21] [22] [23]. This has been largely successful, in that we have helped add substantial value to the companies with which we have worked, on occasions resulting in the owners reportedly realising that value with multi-million dollar sales, eg our work with Memory Corp [24], and Vibtech [25].

The Memory Corp project illustrates the differences and overlaps between innovation, HCD and R\&D. In 1998, the company approached us in Feb 1998 to help them exploit MP3 technology. Later that year other companies brought the first MP3 players to market - expensive and with low storage capacity, and sometimes the subject of law-suits by record companies and software patent owners. Patents already existed on many of the enabling technologies but we worked with the company to identify the needs of those who both listen to music and those who create it, identified novel areas and three initial patent filings were made in 1999. Products were brought to market in 1999 (Soulmate, a MP3 player) and 2000 (MusicStore, a CD ripper, hard disk storage and docking station - discussed in [26]). The CEO of the company considered the company's innovations to be market-led rather than technologyled, and, while there was some R\&D expenditure, our input and much of the budget was "industrial design" or "marketing for new or improved products" ie non-R\&D, according to the OECD. In early 2000, the company sold this part of the business for a reported $\$ 10 \mathrm{~m}$. We then worked with the new company to address usability issues of both the devices and digital rights management (DRM), seeking a balance between the listener's interests and the artists and those who act on their behalf (eg record companies, publishers). This involved participating in a global initiative - SDMI - which evolved a number of pragmatic approaches to incorporate DRM in devices - which in turn informed Apple's development, in mid2001, of the first iPod. The iPod can also be classed, in OECD terminology, as an "improved product". It was not the smallest MP3 player to date, not the one with most storage capacity or (according to reviewers) the best sound quality but certainly contained innovative interactivity and bespoke integrated electronics. Arguably the real innovation was not technical but service-based - the legal availability of mainstream content through iTunes, thanks to DRM that most users found acceptable, but that the content creators accepted as adequate. Many consumers also wanted a "legal MP3 solution", rather than navigate internet piracy. Further work is needed but it seems that most of the HCD-related innovation expenditure by Apple on the iPod would not be classed as R\&D.

In projects since we have come to recognise that knowledge transfer is fundamentally a human-centred activity. This is evident in recognising and respecting the different agendas for each of the three partners in a UK KTP programme - the company (who have fiscal objectives and power structures, and tend to have a policy of "investing in people" - to achieve their aspirations within the company), the knowledge partner (usually a university department with a wide range of interlocking objectives and aspirations) and the associate (the agent of change, and typically a recent graduate in their first graduate-level job, who is provided with a training infrastructure equivalent to a large company's fast-track graduate development scheme).
Aspects of HCD we have found valuable include

- $\quad$ Enabling organisations to carry out human-centred activities, such as ensuring accessibility and usability are considered early in the innovation cycle

- Using scenarios and personas to broaden the company's understanding of its potential market and its needs

- Using research methods such as ethnography and sociotechnical studies (for example longitudinal investigations to identify attitudes towards the use of biometric technology to confirm identity in publicly-located selfservice terminals.)

- Considering the context of use - for example a design constraint for MusicStore, was the user's need to be able to rapidly transfer songs from the base station to the portable MP3 player before leaving the house

- Cross-cultural surveys in order to identify global market issues

Two key challenges have emerged in applying HCD to commercialization work with industry: firstly to convince companies of the validity and practicality of the ideas in HCD (which generally can be addressed by a capable maturity model (CMM) approach) and secondly, fitting HCD into the arbitrary categorizations of activity for which public funding is and is not available.

\subsection{Justifying HCD in a commercial context}

Each of the aspects of HCD useful in knowledge transfer might equally benefit a commercialisation activity. On the face of it, HCD should be the ideal partner for commercial innovation, in particular in identifying the market and how to address its needs. Rather than rely on the traditional approach of advertising and sales staff, if we know peoples' context, needs and desires as well as their expressed requirements, we can innovate products and services to match. An HCD approach might go beyond test-marketing and focus groups into ethnographic studies. In fact industry already does this and has been doing so for many years. Product manufacturers have long used ethnographic techniques to design products, even citing their use [27] in recruitment videos and advertising! Many other commentators (eg [28] highlight companies such as Nokia's commitment to HCD in product innovation.

But since the first stage in ISO 13407 is to create the climate for HCD within an organisation, and most of the companies with which we have worked in KTP have tended to be fairly low in Usability Capability Maturity [29] and often sceptical about the benefits of changing this, we need to acknowledge that HCD influence will be patchy on individual projects. MusicStore illustrates this. The HCD approach led to consulting a wide range of stakeholders for their needs - the user was able to move tracks very rapidly between one device and another; using standard digital rights management (DRM) approaches, the interests of musicians, writers and their publishers were respected; data input exploited norms from mobile phones; a set of software tools enabled unskilled staff in small record labels to release their artists' work safely and profitably. However the exact layout of the device interface was outside the scope of our engagement and defined within the engineering team (where this work would be categorised as R\&D). In evaluation we found that the input panel had an arbitrary left-handed bias! Other usability problems were identified in the controls and the operation of the player for typical scenarios of use and although the knowledge transfer project itself was award-winning, when it came to the products, "a worthy first attempt" [26] was the consensus amongst reviewers. 
In this project the company was largely interested in, and sympathetic to, HCD but in subsequent projects we have encountered antipathy from senior management in organisations who are suspicious of "fuzzy human issues" when they have an objective to get product or services into the market. This experience matches that of [30] who call for HCD to enlarge its scope to address the context of design itself as well as the context of users, and, to summarise their recommendations, we could:

- Teach/share expertise with individuals in order to change the organisation one person at a time;

- Take an entrenched position - say "no" to involvement as it is in neither parties' interests to compromise;

- Effectively to "embrace \& extend" other methodologies for example the Rational Unified Process and Agile/XP approaches can be adapted to incorporate $\mathrm{HCD}$;

- Identify sufficiently senior decision-makers and lobby them effectively so they become HCD champions and gain an organisational commitment. (This pattern was widely advocated in the 1980s for companies seeking ISO 9001 quality accreditation).

Although similar to trying to use HCD in collaborations with industry, our first impressions are that using HCD in university commercialisation will require further refinement. From an ISO 13407 perspective the immediate readiness of the situation to use HCD is very low. This reflects the mutual inexperience of academics, investors and commercialisation staff working together, and terminology can often cause confusion. Yet if the ambitions for "non R\&D" innovation are to be achieved then it will be vital to get the oft-reported financial benefits of using HCD. Evidence, such as [31], has been interesting, but not convincing, for the people with whom we have engaged - the advantages and methods need to be defined more clearly. Three possible short-term strategies emerge to embody human-centred approaches within university commercialisation

- Subversion - exploit the maverick attitudes amongst the entrepreneurial community to follow HCD practices regardless of advice. Practice guerrilla HCD if needs be. If caught out, use the fig leaf of "market focus"

- Proselytise - evangelise the "shiny new path" of HCD. Cite Kees Dorst and companies like the Finland-based Idean as exemplars of how to use the end user to drive innovation

- Damage Reduction - be pragmatic in a designer-centric world. Exploit the motivations of creative designers and technologists. Tame their worst excesses by effective nonthreatening feedback loops based on their influences.

However these are very much tactical responses. Of more interest will be a long term effort to ensure that HCD is as ubiquitous in the dialogue about innovation and economic performance as, say, sustainability

\section{PACT ANALYSIS}

Taking a human-centred approach to university commercialisation, the "People, Activities, Context, and Technology" (PACT) [1] approach provides a framework for a small localised study that might form the basis for a more general study that would be based on ISO13407 and Human Centred Capability Maturity [29] models.

\subsection{People}

The following stakeholders are identified in university commercialisation situations:
1. Permanent members of academic staff, who have different profiles, at different points in their careers, with relatively secure jobs, because they are funded for teaching as well as research: lecturers, senior lecturers, readers, professors.

2. Academics with research-only posts, who are either on short term contracts or are permanent but would be made redundant if new funding cannot be secured - typically research associates, fellows, senior fellows and some professors.

3. Central university administrative support for commercialisation (for example the Knowledge Transfer \& Commercialisation Office) along with university finance and legal advisers.

4. Students nearing graduation who want to work commercialising their research.

5. Staff responsible for public sector funding sources.

6. Individuals offering private sector funding (friends, family, banks, angel investors, and venture capitalists).

7. Consultant advisors offering services such as business planning, market analysis, product definition workshops, training days in IP, finance, recruitment etc

8. Any of the above may have a range of first language, race, religion, political beliefs (in particular socialist $\mathrm{v}$ capitalist, open source $\mathrm{v}$ patenting, green issues etc)

9. Any of the above may have family considerations in particular spouse's careers, children's schools, responsibility for aging parents etc that may constrain geographic or time availability.

\subsection{Activities}

The relevant activities undertaken by these people include

10. Refinement of the idea into a commercial proposition

11. Completing requirements for a $\mathrm{PhD}$ - as well as consolidating the assets to be commercialised, there are many ways in which pursuit of commercialisation or a completed thesis become contradictory objectives.

12. IP ownership debates - clarifying background IP, which in the case of a $\mathrm{PhD}$ may have come from the supervisor or colleagues, and foreground IP, created by the student more or less under the guidance of the supervisor. Similarly, collaborations with companies will yield new IP and exploit old IP from either side. IP ownership should have been agreed in advance but there may be complicating factors (eg company demergers, changes in university policies)

13. Publishing and participating in conferences and workshops, in order to raise profile and gain esteem within a domain.

14. The usual responsibilities of an academic to their employer, learners and their domain. (This might require the "buying out" of academics' time in order to focus on research, and the recruitment of students to work on an aspect of the project)

15. Investigation of potential to protect IP eg patent, trade mark, design right, branding, copyright.

16. Assess freedom to operate (is there a relevant patent in another country, eg USA, that would prevent or constrain operation in that country?

17. Identification of a route to market - this involves identifying a target audience and the packaging and pricing mechanism that would be successful for this audience

\subsection{Context}

The context within which they carry out these activities includes:

18. University IP policies and pre-existing IP agreements. 
19. Promotion criteria within university (typically a stated combination of research, teaching, commercial and admin accomplishments often with an unstated interpretative bias prioritising research.

20. University pay, reward and pension policies. Pensions tend to be final salary based, cost $15-20 \%$ of salary and are not easily ported, especially for junior staff who expect to rise to, say, professor. UK universities have rigid salary scales but also policies to own staff IP but allow exceptional payments of a percentage (typically 20-50\%) of commercial revenues.

21. University recruitment, management and redundancy policies for staff recruited during a commercialisation phase who are not expected to be employed by the university after commercialisation. (Most UK university HR policies are designed to maximise staff retention. Redundancy entitlement for example is typically more generous and is provided sooner than statutory requirements. It may become due at the end of a fixed term project, even when the employee joins a spin-out company).

22. Public sector funding criteria. These are usually stated and reflect government priorities (eg Lambert and R\&D) but can be tempered with pragmatic views of what is achievable in the current climate (and this may have changed since policy was set)

23. Investors' criteria. These tend to form fashions that change each season. The macro-economic climate has a strong influence and a lot will depend on within which sector or niche the proposal is categorised. Risk levels are identified accordingly, and then required rate of return on investment (ROI) - which will vary between $20 \%$ and $80 \%$ per annum (depending on risk) for 4-5 years.

24. Other academic duties. It would be rare for an individual academic to be given $100 \%$ workload allocation to focus on a specific commercialisation project, and so a range of other duties needs to be assumed. As well as a high risk that activities such as teaching preparation, marking and admin exceed time allowed for, these may also lock timeslots each week that reduce flexibility for meetings with investors.

25. Perceived job security may affect key staff. If an RA thinks that a proposed spin-out company may not be funded adequately to succeed and/or will not match their salary aspirations, they may apply for and accept other positions.

\subsection{Technology}

The technology used to carry out these activities includes:

26. Office software packages such as Microsoft Office ${ }^{\circ}$. Thanks to the productivity capabilities of these, detailed and convincing business plans and financial scenarios can be explored and quickly adapted for required audiences.

27. University network, computing and library facilities may be very much better than a start-up company can afford (though equally the reverse can be true), and so detailed research, development and evaluation may need temporary access (which may be costed) to exploit these

28. The preponderance amongst investors and industry generally of push mobile email via proprietary platforms and devices such as Blackberry ${ }^{\circledR}$, Windows Mobile ${ }^{\circledR}$ and

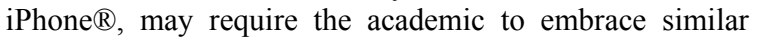
technology to achieve the $24 / 7$ availability required.

29. Third party technology (eg ecommerce web-hosting or sources of copyright geo-data, such as Ordnance Survey ${ }^{\circledR}$ or ViaMichelin) may be required at a cost in order to bring a product or service into the market. Academics will not usually have had experience of procuring such, or negotiating service level agreements.

\subsection{Future Work}

We have now identified 23 potential commercialisation projects within Edinburgh Napier's Centre for Informatics Research at various stages of development, one of which is trading already and three others fast approach that point, with the remainder considered for rolling out over the next five years. With each project we plan to evaluate whether HCD approaches in the early stages, results in any commercial benefits and whether the resulting trading entity continues to embody HCD values.

We invite responses on how the HCI community can contribute to the humanising of the innovation and commercialisation processes. We also note that the UK HCI community appears to have had a higher level of commercial activity than other aspects of computing and plan to study this to identify whether HCI academics are indeed better suited to this, and any critical success factors. So far we have only considered UK practice in the context of US and European approaches, and more work is needed to address global issues.

\section{ACKNOWLEDGMENTS}

Thanks to the anonymous reviewers, and to Professor David Benyon, whose advice helped focus this paper. The KTP projects here were jointly funded by the companies involved and the various UK funding agencies (eg ESRC, Scottish Government and TSB). Our commercialisation work has been funded by Scottish Enterprise Proof of Concept programmes and the $2 \mathrm{KT}$ project.

\section{REFERENCES}

[1] Benyon, D., Turner, P. and Turner, S. 2005. Designing Interactive Systems. London, UK : Pearson Education Limited.

[2] Crown 2009. KTP - Strategy. [Online]. [Cited: 3 June 2009.] http://www.ktponline.org.uk/strategy/strategy.aspx.

[3] Preston, J.T. 2003. Building success into a high-tech startup. The Industrial Physicist. June 2003, pp. 16-18.

[4] ISO/IEC 1999. ISO 13407 Human-centred design processes for interactive systems. International Organization for Standardization.

[5] OECD 2008. Education at a glance - 2008 OECD indicators. [Online] [Cited: 3 June 2009.] OECD http://www.oecd.org/document/9/0,3343,en_2649_39263 $238 \quad 41266761 \quad 1 \quad 1 \quad 1 \quad 1,00 . h t m l$.

[6] Lambert, Richard 2003. Lambert Review of BusinessUniversity Collaboration. Norwich : HMSO.

[7] Fabrizio, Kira 2006. The Use of University Research in Firm Innovation. In Henry Chesbrough, Wim Vanhaverbeke and Joel West (Eds) Open Innovation: Researching a New Paradigm. Oxford : Oxford University Press 134-160.

[8] NESTA Policy \& Research Unit 2007. Science and Innovation Strategy for Scotland. London : NESTA.

[9] Usai, S. 2008. The geography of inventive activities in OECD regions. Paris : OECD Publications.

[10] Danziger, P. N. 2004. Why People Buy Things They Don't Need: Understanding and Predicting Consumer Behavior. Kaplan Publishing.

[11] Light, A. 2004. HCI 2004 hears the New Rules of Design. Usability News. [Online] [Cited: 27 February 2009.] http://www.usabilitynews.com/news/article1933.asp. 
[12] Hulya, Ulku 2007. R\&D, innovation and output: evidence from OECD and nonOECD countries. Applied Economics, pp. 291-307.

[13] Busse, D. K. 2007. Fast-tracking product innovation. San Jose, CA, USA : ACM, New York, NY, CHI '07 Extended Abstracts on Human Factors in Computing Systems (, April 28 - May 03, 2007). 1703-1708. http://doi.acm.org/10.1145/1240866.1240887.

[14] OECD 2002. Frascati Manual 2002 Proposed Standard Practice for Surveys on Research and Experimental Development. OECD Publishing, 2002.

[15] OECD 2006. Oslo Manual: Guidelines for Collecting and Interpreting Innovation Data, 3rd Edition. OECD Publishing.

[16] Stewart, T. 2009. New Usability Standard Punches its Weight. Usability News. [Online] [Cited: 1 March 2009.] http://www.usabilitynews.com/news/article5411.asp .

[17] Social Enterprise Lexicon 2005. [Online] [Cited: 27 February 2009.] http://www.sealliance.org/resources lexicon.cfm.

[18] McEwan, T., Benyon, D. and Turner, S. 2003. Channelling expertise from Napier's HCI group - humancentred knowledge transfer. In Gray, P., Johnson, H., \& O'Neill, E. (Eds) Proceedings of HCI2003: designing for society Volume 2. Bristol : Research Press.

[19] Schön, Donald 1983. The Reflective Practitioner: How professionals think in action. London : Temple Smith.

[20] Ackerman, M., Pipek, V. and Wulf, V. 2003. Beyond Knowledge Management: Sharing Expertise. Cambridge, MA : MIT Press.

[21] Gaines, B.R and Shaw, M.L.G. 1986. A learning model for forecasting the future of information technology. Future Computing Systems, pp. 31-69.

[22] Griliches, S. 1957. Hybrid Corn: An Exploration in the Economics of Technological Change. Econometrica. 25[4], pp. 501-522.
[23] Moore, G. 1999. Crossing The Chasm, 2nd Edn. Oxford : Capstone Publishing.

[24] Harrison, L. 2000. Memory Corp splits in twain and changes name. The Register. [Online] [Cited: 27 February 2009.] http://www.theregister.co.uk/2000/05/04/memory corp s plits in twain/.

[25] Friedli, D. 2006. Vibtech sale nets rewards for backers. The Scotsman. [Online] [Cited: 27 February 2009.] http://business.scotsman.com/businesstechnology/Vibtech -sale-nets-rewards-for.2815037.jp.

[26] Gowan, W. 2000. MP3 without a PC. About.com. [Online] [Cited: 27 February 2009.] http://pcworld.about.com/news/Nov212000id35406.htm.

[27] Unknown 2001. Hoover Engineering Recruiting Video Script. Wordkraft. [Online] [Cited: 27 February 2009.] http://www.wordkraft.biz/video radio/hoover recruiting. pdf

[28] Mootee, I. 2007. Human Centered Design (HCD) Is Innovation's New Secret Weapon. Marketing \& Strategy Innovation Blog. [Online] [Cited: 27 February 2009.] http://blog.futurelab.net/2007/08/human_centered_design hed is i.html.

[29] Earthy, J. 1998. Usability Maturity Model: Human Centredness Scale. s.l. : EC Telematics Applications Project IE. 2016.

[30] Svanæs, D. and Gulliksen, J. 2008. Understanding the context of design: towards tactical user centered design. In Proceedings of the 5th Nordic Conference on HumanComputer interaction: Building Bridges (Lund, Sweden, October 20 - 22, 2008). NordiCHI '08, vol. 358. ACM, New York, NY, 353-362. DOI= http://doi.acm.org/10.1145/1463160.1463199.

[31] Nielsen, J. and Gilutz, S. 2003. Usability Return on Investment. Nielsen Norman Group. 